\title{
A PERSPECTIVA CTS E A ABORDAGEM DE QUESTÕES SOCIOCIENTÍFICAS NO ENSINO DE CIÊNCIAS: APROXIMAÇÕES E DISTANCIAMENTOS
}

\section{The STS Perspective and the Approach of Socio Scientific Issues in the Teaching of Sciences: Approximations and Distances}

\author{
João Paulo Fernandes ${ }^{1}$ \\ Guaracira Gouvêa ${ }^{2}$
}

\begin{abstract}
Resumo: Uma das linhas de pesquisa no contexto do Ensino de Ciências que tem merecido bastante visibilidade nos últimos anos é a dos estudos de Ciência-Tecnologia-Sociedade (CTS), pela sua relevância social e cultural, assim como a abordagem de Questões Sociocientíficas (QSC). Neste sentido, o objetivo deste artigo é promover uma discussão, por meio de um ensaio teórico, envolvendo a perspectiva CTS e as QSC no Ensino de Ciências, sem a pretensão de discuti-los exaustivamente, considerando também o caráter heterogêneo da discussão no campo de pesquisa em questão. Apresentamos, ao longo desse texto, a discussão CTS, suas vertentes e as aproximações e os distanciamentos com relação à discussão de QSC. Pretendemos estabelecer diálogos com autores da área da literatura nacional e internacional no contexto da pesquisa em Ensino de Ciências, autores estes precursores desses temas e que nos forneceram subsídios para a discussão presente no artigo. Observamos que um ponto comum entre tais referenciais é a proposta de um Ensino de Ciências que contribua para uma maior autonomia dos indivíduos e o desenvolvimento do caráter crítico, que abordem questões de cunho político, moral e ético de temas que estão relacionados com a ciência e a tecnologia. Em uma discussão de âmbito nacional, as questões sociocientíficas aparecem como temas relativos à perspectiva CTS e no desenvolvimento de discussões que contribuam para o ensino no que se refere à reflexão sobre o papel social da ciência.
\end{abstract}

Palavras-chave: Ciência-Tecnologia-Sociedade. Questões Sociocientíficas. Ensino de Ciências.

\begin{abstract}
One of the lines of research in the context of Science Education that has deserved a lot of visibility in the years is that of Science-Technology-Society (STS) studies, due to its social and cultural promotion, as well as the approach to Sociocientific Issues (SSI). In this sense, the objective of this article is to promote a theoretical discussion, through a theoretical essay, involving a STS perspective and the SSI approach in Science Teaching, without the intention of discussing them exhaustively, also considering the heterogeneous character of the

\footnotetext{
${ }^{1}$ Docente na Graduação Licenciatura em Física no CEFET/RJ, Campus Petrópolis. Doutor em Educação em Ciências e Saúde pelo Núcleo de Tecnologia Educacional para a Saúde (NUTES/UFRJ). Professor no Centro Federal de Educação Tecnológica Celso Suckow da Fonseca - CEFET/RJ. Orcid: 0000-0001-9987-8312. E-mail: joao.fernandes@cefet-rj.br.

2 Pesquisadora credenciada-docente colaboradora no Programa de Pós-Graduação em Educação em Ciências e Saúde da Universidade Federal do Rio de Janeiro. Líder do grupo de pesquisa, Educação, Discurso e Mídia, cadastrado no CNPq, desde 2006. Doutora em Educação, Gestão e Difusão em Biociências pela Universidade Federal do Rio de Janeiro (UFRJ), professora titular da Universidade Federal do Estado do Rio de Janeiro UNIRIO. Orcid: 0000-0001-5955-6992. E-mail: guaracirag@uol.com.br.
} 
discussion. in the research field in question. We present, throughout this text, a STS perspective, its main aspects and the approximations and distances in relation to the SSI approach. We intend to establish dialogues with authors from the area of national and international literature in the context of research in Science Education, authors who are the forerunners of these themes and who provided us with theoretical subsidies for the discussion present in the article. We note that a common point among such theoretical references is the proposal for a Science Teaching that contributes to a greater autonomy of requirements and the development of a critical character, addressing issues of a social, political, moral and ethical nature of themes that are related to science and technology. In a nationwide discussion as socio-scientific issues appear as themes related to the approach from the STS perspective and in the development of impact that contributes to teaching with regard to reflection on the social role of science.

Keywords: Science-Technology-Society. SocioScientific Issues. Science Teaching.

\section{Introdução}

Uma das linhas de pesquisa no contexto do Ensino de Ciências que tem merecido bastante visibilidade nos últimos anos é a dos estudos de Ciência-Tecnologia-Sociedade (CTS), pela sua relevância social e cultural. Devemos considerar também a diversidade de propostas pedagógicas desenvolvidas tendo como base teórica tal discussão nas escolas e nas práticas de ensino, como afirmam Fernandes e Gouvêa (2018), e essas práticas são incorporadas por meio das propostas curriculares, problematizando aspectos que ainda não tinham sido discutidos dentro do contexto da Ciência e Tecnologia (C\&T).

Atualmente podemos observar também pesquisadores se apropriando teoricamente de temas sociocientíficos com enfoque no Ensino de Ciências (SANTOS; MORTIMER, 2009). Tal aspecto envolve questões referentes à Ciência e Tecnologia com grande impacto na sociedade.

Neste sentido, o objetivo deste artigo é promover uma discussão, por meio de um ensaio teórico, envolvendo o movimento CTS e as Questões Sociocientíficas (QSC) no Ensino de Ciências (EC). Apresentamos, ao longo deste texto, a discussão CTS, suas principais vertentes e as aproximações e os distanciamentos com relação à abordagem de QSC.

Salientamos que o presente trabalho se constitui em um ensaio e, por isso, focaremos na exposição de ideias e pontos de vistas sobre os temas, sem a pretensão de discuti-los exaustivamente, considerando também o caráter heterogêneo da discussão no campo de pesquisa em Ensino de Ciências.

Ao longo do texto, buscamos estabelecer diálogos com autores da área da literatura nacional e internacional na área de pesquisa em Ensino de Ciências, alguns precursores da abordagem CTS e da QSC e que nos forneceram subsídios para a discussão desses temas. Da perspectiva CTS são eles: Aikenhead (1994; 2003); Santos e Mortimer (2000); Romero e Diaz, (2002); Auler (2003); Auler e Delizoicov (2006); Santos (2007); Dagnino (2008); Cachapuz et al. (2008); Angotti e Auth (2001); Bernardo (2008). Da discussão de QSC, são eles: Sadler (2004); Ziedler, Sadler e Holmes (2005); Bingle e Gaskell (1994); Reis e Galvão (2008); Santos e Mortimer (2009); Ratcliffe e Grace (2003); Simonneaux, J. e Simonneaux, L. (2011); Robottom e Simonneaux (2012); Sadler (2004); Santos, Amaral e Maciel (2012)

Inicialmente apresentamos uma discussão sobre a perspectiva CTS, apontando sua relevância para o Ensino de Ciências. Em um segundo momento, apresentamos sua inserção no campo curricular, suas estruturas teóricas e as metodologias utilizadas para sua materialização 
no espaço escolar. Em um terceiro momento, apresentamos e conceituamos a abordagem das QSC e suas diferentes vertentes.

Concluímos este trabalho com uma síntese do que foi apresentado com base na literatura e apontamos os distanciamentos e aproximações das duas vertentes a partir de autores que compõem fontes primárias para o desenvolvimento e implementação de propostas didáticas em sala de aula (FERNANDES; GOUVÊA, 2018).

\section{A perspectiva ciência-tecnologia-sociedade (CTS)}

É amplamente discutido na literatura (SANTOS; MORTIMER 2002; BERNARDO, 2008) que a Ciência e Tecnologia (C\&T), apesar de contribuir para a melhoria da nossa qualidade de vida, também auxilia no aumento das desigualdades. Comunidades privilegiadas economicamente se apoderam dos conhecimentos da C\&T mais rapidamente, transformandoos em instrumentos de poder e de controle sobre sociedades mais vulneráveis.

A problematização dos objetivos da formação científica de estudantes de professores nas escolas surge, principalmente, em um contexto de tensão social gerado pelo pós-guerra, com o lançamento das bombas nucleares e pela guerra fria, entre as décadas de 1940, 1950, 1960 e 1970, e também com a preocupação mundial do uso da ciência e da tecnologia para fins armamentistas.

O enfoque CTS surgiu, em meados da década de 1960, como um movimento de renovação curricular, tendo como principal foco promover a discussão sobre: os objetivos da formação científica e tecnológica de estudantes nas escolas; os processos que envolvem o ensino e aprendizagem de Ciências; a formação dos professores e o desenvolvimento de políticas públicas educacionais (AIKENHEAD, 2003).

O Enfoque CTS vem ganhando cada vez mais visibilidade com o aumento da demanda por uma formação do aluno e futuro cidadão, que possa contribuir, dessa forma, para maiores enfrentamentos dos problemas postos no atual contexto e suas interfaces no campo científico.

Entendemos que práticas educativas que promovam a formação para a cidadania possam proporcionar mais oportunidades de engajamento social, tornando a população cada vez mais consciente dos problemas em dimensão global, capacitando-a para exercício da cidadania. Para isso, se faz necessário, que o professor tenha formação necessária, proporcionando aos seus alunos uma visão de forma ampla.

Tendo como base os debates ocorridos no campo acadêmico, sobre questões da natureza da ciência e da tecnologia, o movimento CTS foi se constituindo no ensino. É importante destacar, também, que a discussão dos problemas socioambientais, alertados pelos movimentos ambientalistas, assim como os trabalhos acadêmicos no campo da Filosofia e da Sociologia da Ciência constituem, também, os pressupostos do ensino CTS.

Segundo Santos e Mortimer (2002), desde a década de 1960, há um movimento mundial de estruturação e desenvolvimento de currículos com ênfase CTS no contexto do ensino de ciências. Esses, em sua essência, promovem uma formação para o exercício da cidadania e os aspectos científicos associados ao contexto em que eles se inserem.

Yager (1996) afirma, em seus estudos, que o movimento CTS tem procurado educar os alunos sobre a interdependência destes três domínios (ciência, tecnologia e sociedade, pelo menos desde o início de 1980) e está centralizada no desenvolvimento curricular do ensino de ciências. 
Esse modelo de abordagem nos faz refletir sobre a interação de alguns temas, que, do ponto de vista de um currículo sem o enfoque CTS, não seria feita. O quadro 1 aponta alguns esclarecimentos referente ao CTS, relacionando aspectos sobre o Ensino de Ciências e esclarecendo suas múltiplas conceituações.

Quadro 1 - Aspectos CTS

\begin{tabular}{|l|l|}
\hline \multicolumn{1}{|c|}{ Aspectos de CTS } & \multicolumn{1}{c|}{ Esclarecimentos } \\
\hline $\begin{array}{l}\text { 1. Efeito da Ciência sobre a } \\
\text { Tecnologia }\end{array}$ & A produção de novos conhecimentos tem estimulado mudanças tecnológicas. \\
\hline $\begin{array}{l}\text { 2. Efeito da Tecnologia sobre a } \\
\text { Sociedade }\end{array}$ & $\begin{array}{l}\text { A tecnologia disponível a um grupo humano influencia o estilo de vida desse } \\
\text { grupo. }\end{array}$ \\
\hline $\begin{array}{l}\text { 3. Efeito da Sociedade sobre a } \\
\text { Ciência }\end{array}$ & $\begin{array}{l}\text { Por meio de investimentos e outras pressões, a sociedade influencia a direção } \\
\text { da pesquisa científica. }\end{array}$ \\
\hline $\begin{array}{l}\text { 4. Efeito da Ciência sobre a } \\
\text { Sociedade }\end{array}$ & $\begin{array}{l}\text { O desenvolvimento de teorias científicas pode influenciar a maneira como as } \\
\text { pessoas pensam sobre si próprias e sobre problemas e soluções. }\end{array}$ \\
\hline $\begin{array}{l}\text { 5. Efeito da Sociedade sobre a } \\
\text { Tecnologia }\end{array}$ & $\begin{array}{l}\text { Pressões públicas e privadas podem influenciar a direção em que os } \\
\text { problemas são resolvidos e, em consequência, promover mudanças } \\
\text { tecnológicas. }\end{array}$ \\
\hline $\begin{array}{l}\text { 6. Efeito da Tecnologia sobre a } \\
\text { Ciência }\end{array}$ & $\begin{array}{l}\text { A disponibilidade dos recursos tecnológicos limitará ou ampliará os } \\
\text { progressos científicos. }\end{array}$ \\
\hline
\end{tabular}

Fonte: McKAVANAGH; MAHER 1982. p.72. apud MORTIMER; SANTOS (2002)

Aikenhead (1994), em seus estudos, afirmou que o CTS, quando inserido no ensino de ciências, gera a imagem de conhecimento socialmente construído. O autor enfatiza a discussão de habilidades e conceitos da ciência tradicional, buscando a integração do conteúdo científico em contextos sociais e tecnológicos, tornando assim o tema mais significativo para os alunos.

A literatura, tanto nacional quanto internacional, nos indica que o enfoque CTS faz parte de uma reforma global no Ensino de Ciências, conforme afirmam Romero e Diaz (2002):

O movimento Ciência-Tecnologia-Sociedade (CTS), movimento internacional de reforma do ensino das ciências, que se tem desenvolvido desde meados da década de 1980, engloba ênfases curriculares que requerem metodologias e abordagens inovadoras de ensino de ciências para efectivamente promoverem o desenvolvimento de literacia científica e tecnológica. (ROMERO; DIAZ, 2002, p.4)

De acordo com Garcia, Cerezo e López (1996), a perspectiva CTS apresenta-se em termos globais de duas linhas distintas. A primeira a se considerar é a Norte-Americana, e sua principal característica está em destacar os impactos gerados por inovações tecnológicas, assim como também suas influências sobre a forma de vida dos cidadãos e das instituições.

A segunda é a Linha CTS Europeia. Esta possui grande ênfase na dimensão social que antecede um determinado desenvolvimento científico ou tecnológico, evidenciando diversos fatores, dentre eles, econômicos, políticos, culturais e ambientais que participam do nascimento das teorias científicas que por sua vez contribuem para que seja desenvolvida uma nova tecnologia ou até mesmo para o seu aprimoramento (GARCIA, CEREZO; LÓPEZ, 1996). 
Dagnino (2008), em um amplo estudo sobre CTS e política científica e tecnológica na Ibero-América, indica uma terceira abordagem do tema que é a discussão baseada no Pensamento Latino-Americano em CTS (PLACTS). Segundo esse autor, as discussões iniciais sobre problemas relacionados a C\&T começaram, no Brasil, a partir de meados da década de 60. Essa discussão foi estimulada por ações de C\&T e tinham como objetivos incentivar a participação da sociedade na tomada de decisões, orientar a pesquisa para o atendimento das necessidades da maioria da população, utilização de fontes alternativas de energia, entre outros problemas emergentes daquela época e que até hoje estão presentes.

É importante destacar que o PLACTS nasceu a partir dos pensamentos norte-americanos e europeus, sendo inseridos dentro do contexto de cada país, como destaca Dagnino (2008):

\begin{abstract}
Contribuindo com o verbete "Perspectivas Ibero-americanas" de uma importante Enciclopédia de Ciência Tecnologia e Ética recentemente publicada, López (2005: 976-7) escreve que: "as subculturas CTS, sejam disciplinares ou ativistas, originadas no final dos anos de 1960 e início dos de 1970 no Reino Unido e nos EUA, e de lá transferidas a outros países industrializados durante os anos de 1980 e de 1990 penetraram nas instituições acadêmicas e educacionais dos países europeus mais periféricos, tais como Espanha ou Portugal, e outras regiões periféricas, tais como a América Latina". Nesta passagem, ao afirmar que "as subculturas CTS penetraram nas instituições da América Latina” apenas “durante os anos de 1980 e de 1990”, o autor dá a entender que antes desta época não havia uma reflexão CTS na região. (DAGNINO, 2008, p. 22).
\end{abstract}

Considerando uma visão mais global, podemos afirmar que a abordagem CTS pretende discutir a influência dos avanços em C\&T e possíveis impactos, incluindo fatores econômicos, políticos, culturais.

Não podemos desprezar a questão ambiental que está relacionada com o desenvolvimento científico e tecnológico e que, ao longo do tempo, vem ganhando força dentro da discussão em CTS. Pela sua importância e destaque, alguns autores (VILCHES; PEREZ, 2011; SANTOS, 2007) passam a usar a sigla CTSA, com o objetivo de evidenciar os problemas socioambientais.

\title{
3 A perspectiva CTS e sua inserção no currículo
}

Segundo Santos e Mortimer (2000), no que se refere ao currículo com ênfase em CTS, o objetivo central é preparar os alunos para o pleno exercício da cidadania. Esta visão caracteriza-se pelo destaque do conteúdo científico no seu contexto. Isso reforça a ideia de que o ensino baseado no movimento CTS deve oferecer ao estudante uma formação crítica e cidadã, contemplando também o conteúdo científico.

Bybee (1987) destaca que o enfoque CTS aplicado no desenvolvimento de propostas deve contemplar a apresentação de conhecimentos da ciência e da tecnologia em situações tanto individuais quanto coletivas, que envolvam a ampliação das pesquisas e a tomada de decisões.

Aikenhead (1994) dedicou-se a analisar diferentes propostas curriculares baseadas no enfoque CTS em vários países do mundo. Os materiais analisados por Aikenhead possuíam, em sua maioria, estruturas organizadas segundo a sequência ilustrada na figura 1, onde a seta mostra os passos da sequência: (1) introdução de um problema social; (2) análise da tecnologia relacionada ao tema social; (3) estudo do conteúdo científico definido em função do tema social e da tecnologia introduzida; (4) estudo da tecnologia correlata em função do conteúdo apresentado; (5) discussão da questão social original. 


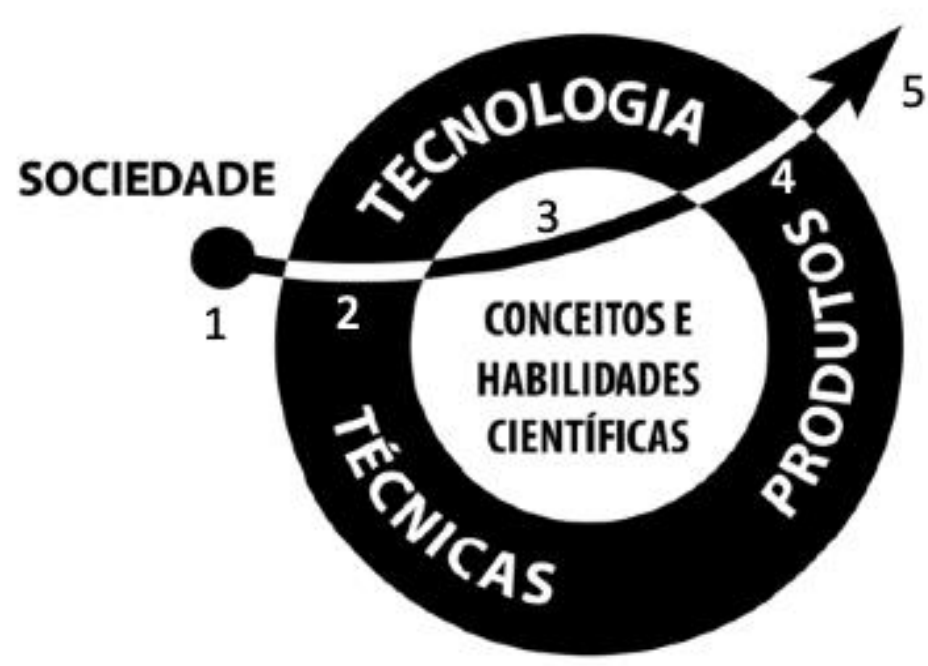

Fonte: Adaptada de AIKENHEAD, 1994, p.57.

O primeiro momento da atividade proposta, tendo como base teórica a perspectiva CTS, consiste na introdução do problema e pode ser realizada a partir de temas de relevância local. É importante ressaltar que os temas sociais incluem a discussão socioambiental, altamente relevante quando consideramos impactos relacionados ao uso de uma determinada tecnologia.

A partir da escolha do problema, o próximo passo é a discussão. Discutido a problemática social, conforme a sequência, devemos articular esse tema com o conteúdo científico. Ele deverá estar relacionado com o problema, sendo indicado o conteúdo científico envolvido no processo.

O terceiro momento dessa abordagem faz referência à tecnologia associada ao conteúdo científico em questão e está também relacionada com o problema social. Essa discussão pode ser feita por meio de exemplos do cotidiano escolar e da comunidade local, aproximando a ciência e a tecnologia do dia a dia do aluno.

Santos e Mortimer (2002) destacam que, ao final, as dimensões sociais do tema são retomadas. Nesse momento, é fundamental explorar os aspectos ambientais, políticos, econômicos, éticos e culturais que estão relacionados com o uso da tecnologia introduzida no início.

Com o intuito de exemplificar como os conteúdos associados a perspectiva CTS integram-se com os conteúdos tradicionais de ciências em várias propostas curriculares, Aikenhead (1994) estabeleceu oito dimensões para os diferentes currículos de CTS, comparando assim essas dimensões com as abordagens tradicionais e que podem ser observadas no quadro 2.

Segundo Mortimer e Santos (2000), as dimensões três e seis são as que representam uma visão de ensino CTS que mais aparecem na literatura do Ensino de Ciências. A dimensão um talvez nem pudesse ser considerada como CTS, já a dimensão oito refere-se a cursos radicais de CTS, em que os conteúdos de ciências quase não são abordados. 
Quadro 2 - Categorias de Ensino em CTS

\begin{tabular}{|c|c|}
\hline Dimensões & Descrição \\
\hline $\begin{array}{l}\text { 1. Conteúdo de } \text { CTS } \\
\text { como elemento de } \\
\text { motivação. }\end{array}$ & $\begin{array}{l}\text { Ensino tradicional de ciências acrescido da menção ao conteúdo de CTS } \\
\text { com a função de tornar as aulas mais interessantes. }\end{array}$ \\
\hline $\begin{array}{l}\text { 2. Incorporação eventual } \\
\text { do conteúdo de CTS ao } \\
\text { conteúdo programático. }\end{array}$ & $\begin{array}{l}\text { Estudo tradicional de ciências acrescido de pequenos estudos de } \\
\text { conteúdo CTS incorporados como apêndices aos tópicos de ciências O conteúdo } \\
\text { de CTS não é resultado do uso de temas unificadores. }\end{array}$ \\
\hline $\begin{array}{l}3 . \quad \text { Incorporação } \\
\text { sistemática do conteúdo } \\
\text { CTS ao conteúdo } \\
\text { programático. }\end{array}$ & $\begin{array}{c}\text { Ensino tradicional de ciências acrescido de uma série de pequenos } \\
\text { estudos de conteúdo de CTS integrados aos tópicos de ciências, com a função de } \\
\text { explorar sistematicamente o conteúdo de CTS. Esses conteúdos formam temas } \\
\text { unificadores. }\end{array}$ \\
\hline $\begin{array}{l}\text { 4. Disciplina Científica } \\
\text { (Química, Física } \\
\text { e Biologia) por meio de } \\
\text { conteúdo de CTS. }\end{array}$ & $\begin{array}{l}\text { Os temas CTS são organizados para organizar os conteúdos de ciências e } \\
\text { sua sequência, mas a seleção do conteúdo científico ainda é feita a partir de uma } \\
\text { disciplina. As listas dos tópicos científicos puros são muito semelhantes àquela da } \\
\text { categoria 3, embora a sequência possa ser bem diferente. }\end{array}$ \\
\hline $\begin{array}{l}\text { 5. Ciências por meio do } \\
\text { conteúdo de CTS. }\end{array}$ & $\begin{array}{l}\text { CTS organiza o conteúdo e sua sequência. O conteúdo de ciências é } \\
\text { multidisciplinar, sendo ditado pelo conteúdo de CTS. A lista de tópicos científicos } \\
\text { puros assemelha-se à listagem de tópicos importantes a partir de uma variedade de } \\
\text { cursos de ensino. O conteúdo relevante de ciências enriquece a aprendizagem. }\end{array}$ \\
\hline $\begin{array}{l}\text { 6. Ciências com conteúdo } \\
\text { de CTS. }\end{array}$ & $\begin{array}{l}\text { O conteúdo CTS é o foco do ensino. O conteúdo relevante de ciências } \\
\text { enriquece a aprendizagem. }\end{array}$ \\
\hline $\begin{array}{l}\text { 7. Incorporação das } \\
\text { ciências ao conteúdo de } \\
\text { CTS. }\end{array}$ & $\begin{array}{c}\text { O conteúdo CTS é o foco do currículo. O conteúdo relevante de ciências } \\
\text { é mencionado, mas não é ensinado sistematicamente. Pode ser dada ênfase aos } \\
\text { princípios gerais da ciência. }\end{array}$ \\
\hline 8. Conteúdo de CTS. & $\begin{array}{l}\text { Estudo de uma questão tecnológica ou social importante. O conteúdo de } \\
\text { ciências é mencionado somente para indicar uma vinculação com as ciências. }\end{array}$ \\
\hline
\end{tabular}

Fonte: AIKENHEAD, 1994 apud MORTIMER; SANTOS, 2002, p.16.

Podemos observar que até a dimensão quatro, o objetivo é um ensino de ciências mais conceitual e, a partir da dimensão cinco, existe uma preocupação na compreensão de aspectos que relacionam as questões entre Ciência, Tecnologia e Sociedade. Nas dimensões seis e sete, as problemáticas estruturam os conteúdos científicos em uma determinada proposta.

Auler e Delizoicov (2006) promovem o enfoque CTS tendo como base teórica os pressupostos do educador Paulo Freire, também definido pelos autores como uma visão humanística Freiriana. Esses pressupostos estão intensamente enraizados na América Latina e no continente Africano. Este estudo aponta para uma discussão que ultrapasse a noção de habilidades e competências, incorporando as dimensões sociais locais nos currículos de ciências.

A dimensão ética, o projeto utópico implícito em seu fazer educacional, a crença na vocação ontológica do ser humano em "ser mais" (ser sujeito histórico e não objeto), eixos balizadores de sua obra, conferem, ao seu projeto político-pedagógico, uma perspectiva de "reinvenção" da sociedade, processo consubstanciado pela participação daqueles que, hoje, encontram-se imersos na "cultura do silêncio", submetidos à condição de objetos ao invés de sujeitos históricos. Freire entende como uma questão ética a constituição de uma sociedade mais democrática, sendo, para tal, necessária a superação da "cultura do silêncio". (AULER; DELIZOICOV, 2006, p. 3). 
Auler e Delizoicov (2006) buscam organizar alguns conteúdos tendo como base os Parâmetros Curriculares Nacionais (PCNs). Essa sistematização, segundo os autores, pode ser realizada a partir da articulação da perspectiva humanística Freiriana e o enfoque CTS. O que podemos observar é que essa discussão estimula a participação da população nos processos de democratização e nas decisões em temas sociais envolvendo a ciência e a tecnologia. Segundo os autores, o objetivo do enfoque CTS contém elementos comuns à matriz teórico-filosófica adotada pelo educador brasileiro Paulo Freire:

\begin{abstract}
Entende-se que, para uma leitura crítica da realidade, do "mundo", pressuposto freiriano, torna-se, cada vez mais, fundamental uma compreensão crítica sobre as interações entre CTS, considerando que a dinâmica social contemporânea está crescentemente vinculada ao desenvolvimento científico-tecnológico. Assim, para uma leitura crítica do mundo contemporâneo, potencializando para ações no sentido de sua transformação, considera-se fundamental a problematização (categoria freiriana) de construções históricas realizadas sobre a atividade científico-tecnológica, consideradas pouco consistentes: superioridade/neutralidade do modelo de decisões tecnocráticas, perspectiva salvacionista/redentora atribuída à Ciência- Tecnologia e o determinismo tecnológico. Tais construções históricas, transformadas em senso comum, particularmente no contexto de nossas investigações, parecem estar exercendo, dentre outras coisas, efeito paralisante, tal qual mitos, aspecto denunciado por Freire. (AULER; DELIZOICOV, 2006, p.4).
\end{abstract}

A visão Freiriana do enfoque CTS nasce no contexto educacional brasileiro, tendo, como pressupostos, a problematização e o exercício de uma análise crítica sobre uma comunidade, com o objetivo de transformar o indivíduo e a sua realidade. Destacamos que o foco principal é uma educação problematizadora, de caráter crítico, na qual o diálogo começaria a partir da reflexão das contradições básicas da situação existencial. É nessa discussão que o diálogo permite a educação para reconhecimento das injustiças sociais e para a prática da liberdade.

É importante destacar a preocupação de autores brasileiros, no desenvolvimento de atividades pautadas no movimento CTS, com a articulação de questões morais e éticas nas discussões que envolvem aspectos da ciência e a tecnologia. Dentre esses enfoques, podemos citar a perspectiva Freiriana de Auler e Delizoicov (2006) e a visão humanística, que também prioriza tais aspectos, desenvolvida por Santos (2007) e descrita anteriormente.

\title{
4 A abordagem de questões sociocientíficas no ensino de ciências
}

Segundo Zeidler, Sadler e Howes (2005), o ensino baseado no CTS tornou-se relativamente difuso ao longo do seu desenvolvimento, consistindo em abordagens baseadas em cursos isolados, caixas de texto em livros didáticos de ciências.

Enquanto CTS tem sido definido como um contexto para o ensino de ciências, a discussão baseada em questões sociocientíficas é citada como uma estratégia pedagógica que em seus objetivos prioriza o letramento científico (SADLER, 2004; ZIEDLER; SADLER; HOLMES, 2005).

Segundo Bingle e Gaskell (1994), o ensino baseado nas questões sociocientíficas está pautado em estimular e promover o desenvolvimento intelectual individual e coletivo, tendo como foco o desenvolvimento de práticas educativas relacionadas às questões morais e éticas que envolvem a Ciência e a Tecnologia.

O ensino baseado nas QSC leva em consideração as questões éticas e construção de julgamentos morais sobre tópicos científicos através da interação social e do discurso. Zeidler et al. (2002) afirmam que a QSC é um termo mais amplo, que engloba tudo o que CTS tem a 

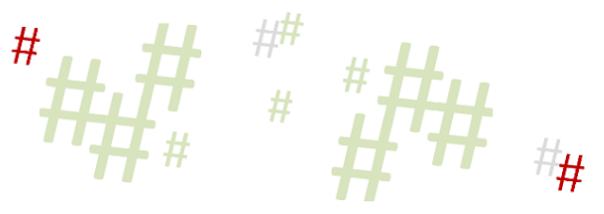

oferecer, indo além, considerando as dimensões éticas da ciência, o raciocínio moral do estudante e o desenvolvimento emocional do estudante.

Segundo Sadler (2004), a temática sociocientífica tem como objetivo não servir apenas como um contexto para a aprendizagem da ciência, mas sim como uma estratégia pedagógica com objetivos melhor definidos, construindo, assim, para uma maior tomada de consciência dos temas científicos e questões sociais:

\begin{abstract}
Vários educadores em ciências têm defendido a inclusão de questões sociocientíficas nas salas de aula de ciências, citando o seu papel central no desenvolvimento de uma cidadania responsável, capaz de aplicação do conhecimento científico e hábitos da mente (Driver, Newton, e Osborne, 2000; Kolstø, 2001a; Zeidler, 1984). Seus esforços para incluir questões sociocientíficas nos currículos de ciência não são a primeira intenção de tornar a sala de aula de ciência mais reflexiva relativa a sociedade e se opondo a visão de uma disciplina isolada e academicamente irrelevante. (SADLER, 2004, p. 2, tradução nossa).
\end{abstract}

Para Zeidler, Sadler e Howes (2005), é possível indicar quatro áreas de importância pedagógica que são centrais para o ensino das QSC: (1) questões sobre a natureza da ciência, (2) questões discursivas em sala de aula, (3) questões culturais, e (4) questões baseadas em caso. Esses problemas podem ser pensados como pontos de entrada no currículo de ciências e podem contribuir para o (5) letramento científico funcional do aluno. Vejamos o esquema na figura 2 (mais abaixo).

Ziedler, Sadler e Howes (2005) mostraram que a educação baseada nas QSC é meio mais efetivo de integrar a Natureza da Ciência, argumentos, valores e julgamentos morais quando comparado com a perspectiva CTS.

Simonneaux, J. e Simonneaux, L. (2011) utilizam-se da expressão "Questions Socialement Vives". Segundo os autores, principalmente na literatura inglesa, a QSC traz consigo a noção de questões socialmente agudas ou questões socialmente vivas (QSV), sendo afirmado que talvez esse aspecto seja mais proativo que a definição de QSC, considerando-a como uma visão francesa para as QSC.

A abordagem de questões socialmente agudas (QSA) e a QSC possuem em comum o potencial para o desenvolvimento de perguntas abertas no contexto de problemas não estruturados e integram o conhecimento na área de ciências humanas. $\mathrm{O}$ ensino baseado em QSA tem por objetivo enfatizar o grau de "agudeza" de uma determinada questão no mundo da pesquisa e/ou sociedade, contribui para o letramento científico e integra análises de risco, análise de padrões de política e governança econômica, tomada de decisão e ação no campo social (SIMONNEAUX, J.; SIMONNEAUX, L., 2011).

Outro ponto relevante no ensino baseado em QSA é a integração da dimensão ambiental no contexto do Ensino de Ciências e isso inclui a discussão de aspectos relacionados ao desenvolvimento econômico sustentável, conservação ambiental, poluição entre outros. Esta abordagem aproxima-se do conceito de CTS revisitado por Hodson (2003), que integra a dimensão ambiental (A), surgindo assim a expressão Ciência-Tecnologia-Sociedade-Ambiente (CTSA). Segundo Simonneaux, J. e Simonneaux, L. (2011), tanto a QSA quanto a CTSA possuem os mesmos objetivos. 
Figura 2 - áreas de importância pedagógica centrais para o ensino das QSC

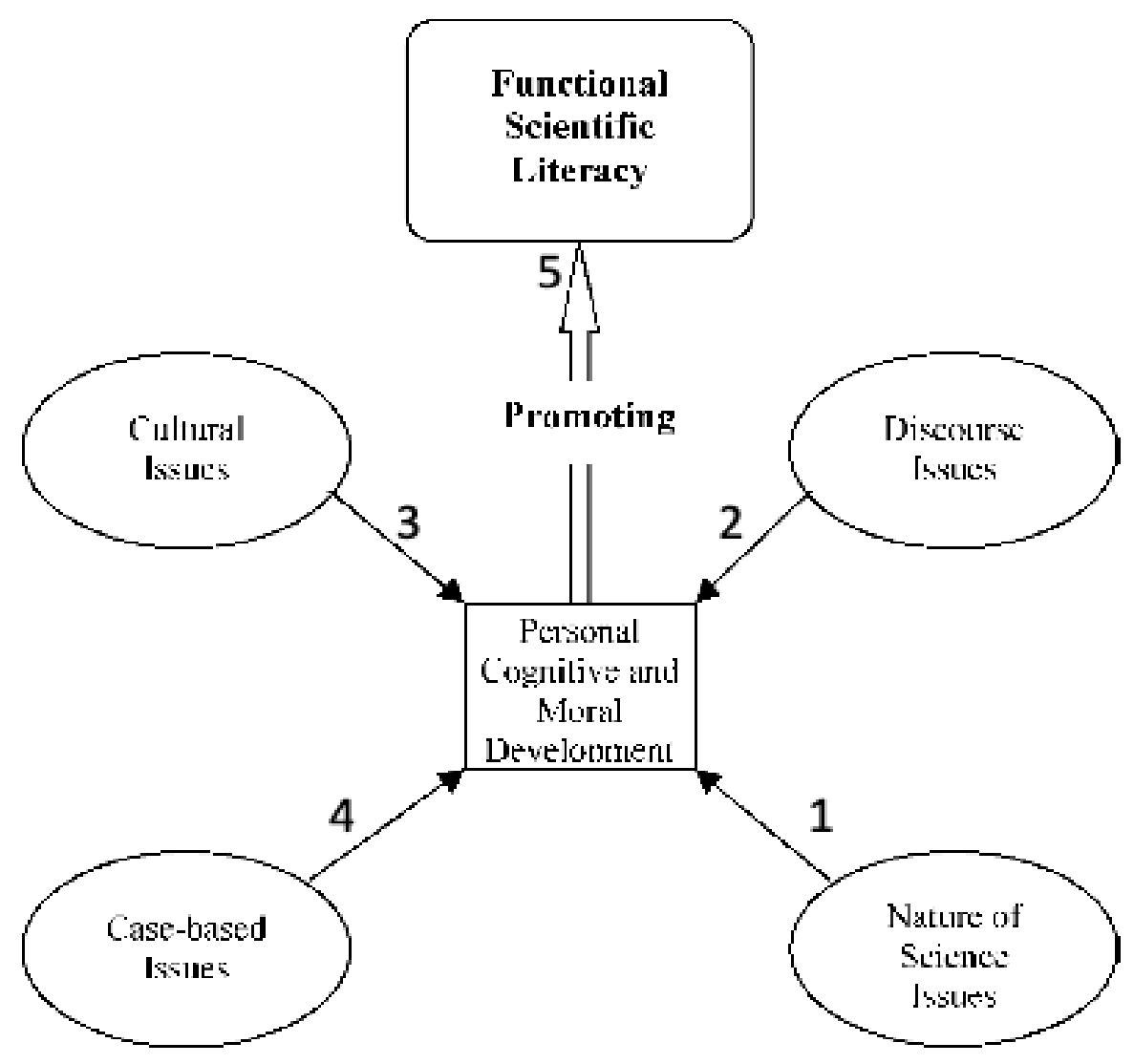

Fonte: ZIEDLER; SADLER; HOWES, 2005, p. 3.

No contexto brasileiro, podemos observar pesquisadores remetendo-se a temas sociocientíficos no contexto do Ensino de Ciências (SANTOS; MORTIMER, 2009). Tal aspecto envolve questões referentes à ciência e tecnologia com grande impacto na sociedade.

São características de um tema sociocientífico: relacionar-se à ciência; envolver formação de opinião e escolhas; ter dimensão local, nacional ou global; envolver discussão de valores e ética; estar relacionado à vida; envolver discussão de benefícios, riscos e valores, entre outras (RATCLIFFE; GRACE, 2003). Assim, a discussão de temas tem sido sugerida para vincular o conhecimento científico à tecnologia e às questões sociais e ambientais, buscando dar significado e relevância ao conteúdo científico (MUNDIN; SANTOS, 2012).

A abordagem dos temas sociocientíficos pode ser feita, ainda, de maneira que os aspectos ambientais, políticos, econômicos, éticos e culturais relativos à ciência e à tecnologia venham a surgir de conteúdos problematizados culturalmente. Isso significa que, nesse caso, eles não são explorados necessariamente como perguntas controversas ou como temas, mas sim como processo constante de tomada de consciência sobre o papel social da ciência (SANTOS; MORTIMER, 2009). Ainda, segundo esses autores:

A introdução de questões ambientais, políticas, econômicas, éticas, sociais e culturais relativas à ciência e à tecnologia tem sido recomendada em currículos com ênfases em Ciência-Tecnologia-Sociedade - CTS (Santos \& Mortimer, 2000), os quais possuem como principal objetivo a formação para a cidadania (Aikenhead, 2006; Santos \& Schnetzler, 1997). Essas questões têm sido geralmente denominadas 
socioscientific issues (SSI) que podem ser traduzidas por questões sociocientíficas ou temas sociocientíficos. (SANTOS; MORTIMER, 2009, p. 2).

Ratcliffe e Grace (2003) afirmam que os temas sociocientíficos podem ser introduzidos a partir de discussões controversas para estimular debates e o posicionamento de estudantes. Segundo os autores, podemos estruturar as atividades pensando em algumas etapas: a primeira, estaria relacionada com a relevância, tendo como objetivo encorajar os alunos a relacionar suas experiências escolares em ciências com problemas de seu cotidiano e desenvolver responsabilidade social. A segunda etapa está voltada para a motivação, tendo como aspecto despertar um maior interesse dos alunos pelo estudo de ciências. Um terceiro momento possui um direcionamento para a comunicação e argumentação e ajuda os alunos a se expressar, ouvir e argumentar. Um quarto momento seria ajudar os alunos a desenvolver raciocínio com maior exigência cognitiva. Por último, auxiliar na aprendizagem de conceitos científicos e de aspectos relativos à natureza da ciência.

Destacamos que um tema deve propiciar uma discussão que gere o compromisso individual e coletivo, sendo relevante que ele tenha um significado real para o estudante. É a partir da discussão de temas reais e da tentativa de se delinear soluções para eles que os estudantes se envolvem de forma significativa e assumem um compromisso social (SANTOS; AMARAL; MACIEL, 2012).

Reis e Galvão (2008) abordam o aspecto das controvérsias sociocientíficas. Tal abordagem, no trabalho em questão, possui relação com a compreensão da natureza da ciência e da sua relação com a sociedade e a cultura e podemos perceber que o referencial CTS é fortemente citado pelos autores, sendo utilizado, também, como referencial teóricometodológico.

Segundo Santos, Amaral e Maciel (2012), os aspectos sociocientíficos estão inseridos no contexto da educação para a cidadania. Tal abordagem pode ser realizada por meio de estratégias de ensino que desenvolvam a participação ou a capacidade de tomada de decisão, tais como: discussão estruturada, fóruns e debates, projetos, pesquisa de campo, ações comunitárias, estudo de casos, dentre outras.

\section{Articulações entre a perspectiva CTS e as QSC}

Apresentamos anteriormente a contribuição de pesquisadores do Ensino de Ciências e suas visões e conceituações sobre a perspectiva CTS e as QSC e podemos observar pontos considerados como convergentes, em alguns momentos, complementares, e, em outros, divergentes.

Observamos que um ponto comum entre tais referenciais é o desenvolvimento de um Ensino de Ciências que contribua para uma maior autonomia dos indivíduos e o desenvolvimento do caráter crítico, que abordem questões de cunho social, político, moral e ético de temas que estão relacionados com a ciência e a tecnologia.

Segundo Santos e Mortimer (2009):

Temos traduzido os chamados socioscientific issues (SSI) por aspectos sociocientíficos (ASC), pois entendemos que questões ambientais, políticas, econômicas, éticas, sociais e culturais relativas à ciência e à tecnologia são inerentes à atividade científica e que a sua abordagem no currículo pode ser feita: de forma temática, no sentido de tópico ou assunto amplo em que essas questões estão imbricadas (e.g. poluição ambiental, transgênicos, recursos energéticos etc.); ou de forma pontual, com exemplos de fatos e fenômenos do cotidiano relativos a conteúdos científicos que ilustram aplicações tecnológicas envolvendo esses aspectos; 

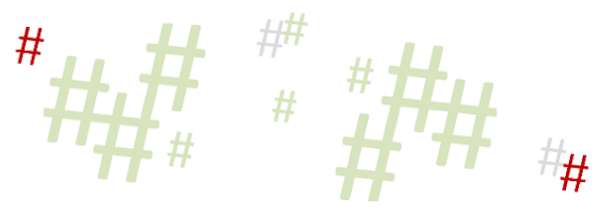

ou ainda por meio de questões dirigidas aos estudantes sobre esses aspectos. (SANTOS; MORTIMER, 2009, p. 2).

É preciso destacar que, no enfoque CTS, busca-se alcançar os aspectos conceituais envolvidos com os conteúdos escolares. Assim, a escolha dos temas sociocientíficos é realizada considerando-se os conceitos científicos que estão vinculados a temas relevantes para a sociedade. A diferença central está no fato de que os conceitos são apresentados de forma integrada aos temas, e não de maneira fragmentada e descontextualizada, que caracteriza a abordagem clássica do atual ensino de ciências (MUNDIN; SANTOS, 2012).

As estratégias de trabalho utilizando temas geradores, apresentadas por Delizoicov, Angotti e Pernambuco (2002), constituem uma proposta de ensino na qual os conteúdos a serem trabalhados são escolhidos com base em um tema.

O tema é escolhido conforme a relevância e emergência que possuem no contexto do
aluno. A partir do tema, os alunos são levados a problematizar ou questionar o
conhecimento que têm inicialmente (senso comum ou cultura primeira), até chegarem
à necessidade do uso do conhecimento científico (conhecimento sistematizado ou
culturalmente elaborado) para a explicação das situações levantadas. Ou seja, o
conceito científico é o ponto de chegada, e o tema, o ponto de partida no processo
educacional. (MUNDIN; SANTOS, 2012, p. 791).

Segundo Mundin e Santos (2012), esse enfoque deve seguir três passos básicos. No primeiro, os alunos são incentivados a pensar e a questionar sobre situações relacionadas com o tema. Em seguida, é realizada a organização do conhecimento. O professor desenvolve a conceituação necessária para o entendimento científico dos pontos levantados e propõe a realização de atividades e exercícios. A aplicação do conhecimento estudado acontece por último e é conduzida tanto para se estudarem as situações iniciais levantadas pelos alunos, quanto para explicar outras situações que podem ter surgido durante a aula.

A situação de estudo é uma tentativa de organização do ensino de ciências por meio da articulação dos conteúdos curriculares entre si e os saberes trazidos do cotidiano dos alunos. Podemos observar que a proposta é centrada nas situações reais dos estudantes. É necessário que haja uma associação entre o conhecimento cotidiano dos alunos e o conhecimento científico. Os conceitos e significados são construídos tendo como ponto de partida a experiência de vida dos alunos, que são incentivados a repensar e reconstruir suas concepções, ampliando a visão de mundo a partir dos processos interativos estabelecidos na sala de aula. A experiência dos alunos torna-se o meio facilitador da interação pedagógica (MUNDIN; SANTOS, 2012).

Segundo Santos e Mortimer (2009), o desenvolvimento dos temas sociocientíficos, no ensino de Ciências, possui, entre seus objetivos, estimular a tomada de atitudes e valores em uma visão humanística. Nesta mesma discussão, podemos citar os trabalhos de Auler e Delizoicov (2001), incorporando ao currículo as discussões de aspectos relacionados a valores e discussões críticas, proporcionando uma educação em que os alunos possam refletir sobre sua condição no mundo frente aos desafios postos pela ciência e tecnologia.

Observamos, principalmente, em uma discussão de âmbito nacional, que as questões sociocientíficas aparecem como temas relativos ao CTS e no desenvolvimento de discussões que contribuam para o ensino no que se refere à tomada de consciência sobre o papel social da ciência.

Santos, Amaral e Maciel (2012) afirmam que os aspectos sociocientíficos são abordados a partir da discussão CTS. Os autores afirmam que a proposta curricular envolvendo as relações CTS corresponde a uma integração entre educação científica, tecnológica em que os conteúdos 
científicos e tecnológicos são estudados em conjunto com a discussão de seus aspectos históricos, éticos, políticos e socioeconômicos (SANTOS; AMARAL; MACIEL, 2012).

Segundo Reis e Galvão (2008), diversos educadores em ciência defendem a inclusão da discussão de questões sociocientíficas nos currículos de ciências. O que tem sido percebido por pesquisadores é a potencialidade que tal abordagem possui tanto na aprendizagem dos conteúdos e dos processos e da natureza da ciência e da tecnologia, como no desenvolvimento cognitivo, social, político, moral e ético dos alunos (LEVINSON, 2012; SADLER, 2004; ZEIDLER; SADLER; HOWES, 2005).

Reis e Galvão (2008) reforçam a ideia de que a discussão de questões sociocientíficas não está dissociada da discussão teórica baseada no movimento CTS, principalmente, quando pensamos em temas de natureza controversa para a população, introduzindo assim a dimensão social na construção e desenvolvimento de práticas pedagógicas.

As principais críticas da perspectiva CTS são identificadas em um âmbito internacional. Em nível nacional, a discussão das QSC surge no contexto da abordagem CTS. Verificamos que Ziedler, Sadler e Howes. (2005) vão além do que a discussão CTS pode oferecer, inserindo questões morais e éticas da ciência, o que segundo nosso ponto de vista pode ser observado em Santos e Mortimer (2009) ao discutir os aspectos sociocientíficos no contexto do movimento CTS.

Não podemos deixar de destacar o caráter polissêmico e diversificado que o CTS adquiriu em sua construção teórica ao longo de sua história. Conforme apontado por Abreu, Fernandes e Martins. (2013), a produção CTS no Ensino de Ciências é diversificada em termos das visões e abordagens o que contribui para uma heterogeneidade neste campo, tornando tais perspectivas plurais e, até mesmo, contraditórias (ABREU; FERNANDES; MARTINS, 2013). Este é o argumento que embasa a afirmação de Zeidler, Sadler e Howes (2005), em que os autores reforçam a ideia de que a perspectiva CTS tornou-se difusa ao longo do tempo, o que levou à construção de cursos isolados e algumas pequenas inserções em livros didáticos.

Concordamos com o caráter diversificado da discussão CTS, porém, não podemos desconsiderar que houve um aumento expressivo de publicações em revistas acadêmicas segundos os estudos realizados por Abreu, Fernandes e Martins (2013).

Esses estudos também indicam um aumento da pesquisa na área, além de inserção de linhas temáticas nos eventos, dentre eles, podemos citar o Encontro Nacional de Pesquisa em Ensino de Ciências (ENPEC), Encontro Nacional de Pesquisa em Ensino de Física (EPEF), Encontro Nacional de Ensino de Química (ENEQ) e o Encontro Nacional de Ensino de Biologia (ENEBIO). Essa maior frequência de publicações contribui para diferentes interpretações desta perspectiva, sendo adaptada a partir das especificidades e demandas em que ela foi ou será desenvolvida.

Simonneaux, J. e Simonneaux, L. (2011) utilizam a expressão QSA para articular com maior ênfase a discussão ambiental afirmando que tanto a abordagem de QSA quanto abordagem de QSC possuem em comum o potencial para o desenvolvimento de perguntas abertas no contexto de problemas não estruturados e integram o conhecimento na área de ciências e humanas. Os autores ainda afirmam que essa discussão se aproxima do conceito baseado na visão CTSA. É interessante observar que:

A diferenciação entre as abordagens CTS e CTSA é ainda objeto de discussão no campo. A dimensão ambiental ganhou mais importância e destaque na pauta das discussões CTS, ao ponto de que alguns pesquisadores acrescentarem a letra A à sigla CTS. No entanto, alguns pesquisadores questionam a necessidade de se evidenciar a dimensão ambiental na sigla CTS, uma vez que na origem da discussão de Ciência, 
Tecnologia e Sociedade, o ambiente já era considerado como elemento constituinte da sociedade. Este é um debate atual dentro do campo e ainda não há consensos estabelecidos com relação à natureza dessas duas abordagens no sentido delas serem excludentes ou não entre si. (ABREU, FERNANDES; MARTINS, 2013, p. 20)

Tanto Simonneaux, J. e Simonneaux, L. (2011) quanto Abreu, Fernandes e Martins (2013) reforçam o argumento de que a dimensão ambiental possui seu destaque em ambas (QSA e CTSA). Outro aspecto relevante a ser destacado é que ambos apontam a perspectiva CTS como uma teoria que estrutura tais abordagens.

Destacamos que os autores que publicaram em língua inglesa e definem propostas baseadas nas QSC possuem opiniões distintas. Há quem defenda que tal enfoque vai além da perspectiva CTS, priorizando o letramento científico e tendo como objetivos centrais a problematização do aspecto moral e ético (SADLER, 2004; ZIEDLER; SADLER; HOLMES, 2005; BINGLE; GASKELL, 1994), porém, esta conceituação não é unanimidade do campo. Podemos observar com os trabalhos de Simonneaux, J. e Simonneaux, L. (2011) a menção teórica a perspectiva CTS no desenvolvimento de propostas que são intituladas como QSC e as Questões Socialmente Vivas (QSV), este último com menção ao CTSA tendo em vista sua ênfase na discussão de aspectos socioambientais.

Com os argumentos apresentados destacamos que tanto o movimento CTS quando a abordagem das QSC destaca as questões morais, éticas, políticas, ambientais entre outras, em sua articulação com os conteúdos das ciências e da tecnologia.

No contexto de publicações nacionais (AULER; DELIZOICOV, 2006; SANTOS, 2007; DAGNINO, 2008; ANGOTTI; AUTH, 2001; BERNARDO, 2008), tendo em vista o caráter específico de desenvolvimento teórico da perspectiva CTS, observamos a associação desta discussão com os trabalhos do educador Paulo Freire, buscando uma formação cidadã que reflita sobre questões da ciência e da tecnologia, reconhecendo as injustiças sociais, com o enfoque na ação sociopolítica e com o objetivo de transformação local.

\section{Considerações Finais}

Objetivamos, por meio deste artigo, destacar os principais aspectos relacionados com o movimento CTS e as Questões Sociocientíficas (QSC) no contexto do Ensino de Ciências (EC) por meio de um ensaio e, neste sentido, apresentamos, ao longo do texto, um conjunto de autores precursores de tais temáticas, construindo assim, uma discussão tendo como foco a apresentação de conceitos teóricos-metodológicos das vertentes apresentadas.

Pensando em uma educação crítica e reflexiva, foi possível destacar que tanto a perspectiva CTS quanto as QSC buscam promover propostas que contribuam para uma maior autonomia dos indivíduos e o desenvolvimento do caráter crítico, que abordem questões de cunho social, político, moral e ético de temas que estão relacionados com a ciência e a tecnologia.

Pensando as especificidades da América Latina, reforçamos a visão Freiriana do enfoque CTS, que tem sua origem no contexto educacional brasileiro, tendo como pressupostos teóricos a problematização e o exercício de uma análise crítica sobre sua comunidade, com o objetivo de transformar o indivíduo e a sua realidade. É nessa discussão que o diálogo permite a educação para reconhecimento das injustiças sociais e para a prática da liberdade e se constitui como um Pensamento Latino Americano em CTS(PLACTS).

Apesar dos autores que discutem as QSC afirmarem que tal perspectiva possui maior ênfase em questões morais e éticas relacionadas com a ciência, não podemos deixar de destacar 
a ênfase no desenvolvimento de atividades pautadas na perspectiva CTS, tendo como objetivo a associação de questões sociais nas discussões que envolvem aspectos da ciência e da tecnologia. Dentre esses enfoques, podemos citar a visão Freiriana de Auler e Delizoicov (2006) e a humanística que também prioriza tais abordagens e que é desenvolvida por Santos e Mortimer (2007).

Destacamos o caráter polissêmico da discussão no campo de pesquisa em EC, e foi possível observar aspectos convergentes e divergentes a partir da discussão realizada ao longo do presente artigo. Focamos principalmente na exposição de ideias e pontos de vistas sobre os temas, sem a pretensão de discuti-los exaustivamente, conforme apontado inicialmente.

\section{Referências}

ABREU, T. B.; FERNANDES, J. P.; MARTINS, I. Levantamento Sobre a Produção CTS no Brasil no Período de 1980-2008 no Campo de Ensino de Ciências. Alexandria, v. 6, n. 2, p. 3-32, 2013.

AIKENHEAD, G. What is STS Teaching? In: SOLOMON, J.; AIKENHEAD, G. STS Education: International Perspectives on Reform. New York: Teachers College Press, 1994.

AIKENHEAD, G. (Eds.). STS Education: international perspectives on reform. New York: Teachers College Press, 1994.

ANGOTTI, J.A.P.; AUTH, M.A. Ciência e Tecnologia: implicações sociais e o papel da Educação. Ciência e Educação, v.7, n.1, 2001. Disponível em:

http://www.scielo.br/scielo.php?script=sci_arttext\&pid=S1516-73132001000100002. Acesso em: 22 jan. 2018.

AULER, D.; DELIZOICOV. Educação CTS: Articulação entre pressupostos do educador Paulo Freire e Referenciais ligados ao movimento CTS. Les relaciones CTS en la Educación Científica, 2006. Disponível em:

www.educadores.diaadia.pr.gov.br/arquivos/File/2010/artigos_teses/Pedagogia2/aeducacao_c ts.pdf. Acesso em: 23 jan. 2020.

BERNARDO, J. R. R.; A construção de estratégias para abordagem do tema Energia a luz do enfoque Ciência - Tecnologia - Sociedade (CTS) junto a professores de Física do ensino médio. 2008. Tese (Doutorado em Ensino de Biociências e Saúde) - Instituto Oswaldo Cruz, Rio de Janeiro, 2008.

BYBEE, R.W. Science Education and the Science-Technology-society (STS) theme. Science Education, v. 71, n. 5, p. 667-683, 1987.

BINGLE, W.H.; GASKELL, P.J. Scientific Literacy for Decision making and the Social Construction of Science Knowledge. Science Education, v. 78, n. 2, p. 185-201, 1994.

CACHAPUZ, A. et al. Do Estado da Arte da Pesquisa em Educação em Ciências: Linhas de Pesquisa e o Caso "Ciência-Tecnologia-Sociedade". Alexandria, v.1, n.1, p. 27-49, 2008. Disponível em: alexandria.ppgect.ufsc.br/files/2012/03/CACHAPUZ.pdf. Acesso em: 06 dez. 2019. 
DAGNINO, R. As Trajetórias dos Estudos sobre Ciência, Tecnologia e Sociedade e da Política Científica e Tecnológica na Ibero-América. Alexandria. v.1, n.1, p. 3-36, 2008. Disponível em: https://periodicos.ufsc.br/index.php/alexandria/article/view/37483. Acesso em: 20 fev. 2020.

DELIZOICOV, D.; ANGOTTI, J. A.; PERNAMBUCO, M. M. Ensino de ciências: fundamentos e métodos. São Paulo: Cortez, 2002.

FERNANDES, J. P.; GOUVÊA, G. A perspectiva CTS e o desenvolvimento de propostas pedagógicas no contexto do ensino de ciências. Alexandria, Florianópolis, v. 11, n. 2, p. 231255, nov. 2018. Disponível em:

https://periodicos.ufsc.br/index.php/alexandria/article/view/1982-5153.2018v11n2p231. Acesso em: 26 ago. 2020.

GARCIA, M.; CEREZO, J.; LÓPEZ, J. Ciência, Tecnologia y Sociedad. Madrid: Tenos, 1996.

HODSON, D. Time for action: Science Educacion for an Alternative Future. International Journal of Science Education, v. 25, n. 2, p. 27-30, 2003.

LEVINSON, R. A Perspective on Knowing about Global Warming and a Critical Comment about Schools and Curriculum in Relation to Socio-scientific Issues. Cultural Studies of Science Education, v. 7, n. 3, p. 693-701, 2012.

YAGE, R. E. History of Science/Technology/Society as Reform in the United States. In: YAGER, R. E. (Ed.), Science/Technology/Society: as a Reform in Science Education. New York: State University of New York, 1996.

MUNDIM, J. V.; SANTOS, W. L.P. Ensino de ciências no ensino fundamental por meio de temas sociocientíficos: análise de uma prática pedagógica com vista à superação do ensino disciplinar. Ciência \& Educação, v.18, n .4, p. 787-802, 2012. Disponível em: http://www.scielo.br/scielo.php?pid=S151673132012000400004\&script=sci_abstract\&tlng=pt. Acesso em: 10 out. 2019.

RATCLIFFE, M.; GRACE, M. Science Education for Citizenship: Teaching Socioscientific issues. Maidenhead: Open University Press, 2003.

ROBOTTOM, I.; SIMONNEAUX, L. Editorial: Socio-Scientific Issues and Education for Sustainability in Contemporary Education. Research in Science Education, v. 42, n. 1, p. 14, 2012.

REIS, P.; GALVÃO, C. Os professores de ciências naturais e a discussão de controvérsias sociocientíficas: dois casos distintos. Revista Electrónica de Enseñanza de las Ciencias. v. 7, n.3, 2008. Disponível em: http://reec.uvigo.es/volumenes/volumen7/ART13_Vol7_N3.pdf. Acesso em: 20 maio 2020.

ROMERO, A, P.; DÍAZ, J.A. Proyectos y materiales curriculares para la educacion CTS: enfoques, estructuras, contenidos y ejemplos. Bordon, Madri, v. 54, n. 1, p. 5-18, 2002. 
SADLER, T. D. Informal reasoning regarding socioscientific issues: A critical review of research. Journal of Research in Science Teaching, v. 41, p. 513- 536, 2004

SANTOS, L. P.; MORTIMER, E. F. Uma análise de pressupostos teóricos da abordagem CT-S (Ciência - Tecnologia - Sociedade) no contexto da educação brasileira. Ensaio: Pesquisa em Educação em Ciências, v. 2, n. 2, 2002. Disponível em:

www.portal.fae.ufmg.br/seer/index.php/ensaio/article/viewArticle/21. Acesso em: 05 dez. 2020 .

SANTOS, W. L. P. Educação científica na perspectiva de letramento como prática social: funções, princípios e desafios. Revista Brasileira de Educação. v. 12, n. 36, 2007.

Disponível em: http://www.scielo.br/pdf/rbedu/v12n36/a07v1236.pdf. Acesso em: 19 jan. 2020.

SANTOS, L. P.; MORTIMER, E. F. Abordagem de aspectos sociocientíficos em aulas de Ciências: possibilidades e limitações. Investigações em Ensino de Ciências, v. 14, n. 2, p.191-218. 2009. Disponível em: https://www.if.ufrgs.br/cref/ojs/index.php/ienci/article/view/355. Acesso em: 20 ago. 2020.

SIMONNEAUX, J.; SIMONNEAUX, L. Educational Configurations for Teaching Environmental Socioscientific Issues within the Perspective of Sustainability. Research in Science Education, v. 42, n. 1, p. 75-94, 2011.

SANTOS, M. S; AMARAL, C. L. C; MACIEL, M. D. Tema Sociocientífico "Cachaça” em aulas práticas de química na Educação Profissional: uma abordagem CTS. Revista Ensaio, v. 14, n. 1, p. 227-239. 2012. Disponível em www.portal.fae.ufmg.br/seer/index.php/ensaio/article/viewFile/308/806. Acesso em: 11 dez. 2019.

ZEIDLER, D. et al. Beyond STS: A Research-Based Framework for Socioscientific Issues Education. Wiley Periodicals, n. 89, p. 357-377, 2005.

Recebido em agosto de 2020.

Aprovado em novembro de 2020. 